\title{
Blind dating - mate finding in planktonic copepods. II. The pheromone cloud of Pseudocalanus elongatus
}

\author{
Thomas Kiørboe $^{1, *}$, Espen Bagøien ${ }^{1,2}$, Uffe Høgsbro Thygesen ${ }^{1}$ \\ Danish Institute for Fisheries Research, Kavalergården 6, 2920 Charlottenlund, Denmark \\ Present address: Department of Biology, University of Oslo, PO Box 1066 Blindern, 0316 Oslo, Norway
}

\begin{abstract}
Receptive females of Pseudocalanus elongatus, like many other planktonic copepods, produce pheromones to signal their presence and position to males, and thus enhance the rate of mate encounter. By means of 3D video recordings we describe how a characteristic behaviour is elicited in males that encounter the pheromone signal of a female. For several minutes the male speeds around the female along zigzagged and looped swimming trails. Every 10 to $20 \mathrm{~s}$ he approaches the female, slows down, and makes physical contact with her. Between visits, the male makes long excursions that may take him up to $15 \mathrm{~mm}$ away from her. The multiple excursions define a near-spherical volume around the female within which he is capable of navigating back to her. During courtship the female hovers, but she frequently changes her body orientation and, thus, the direction of her feeding current, which also causes her to move a little. Due to this small-scale dance of the female, pheromones are constantly being spread in different directions and from constantly shifting positions. Based on male and female behaviour and simple advection-diffusion models, we characterise the pheromone plume surrounding the female as an almost spherical cloud with a very heterogeneous internal structure. This is very different from the long, distinct pheromone trails deposited by females of many cruising copepods and appears to be characteristic of hovering females. We estimate the encounter cross-section area of the pheromone plume of $P$. elongatus and find that it enhances the mate encounter probability by a factor of about 40 , and we show that this area increases in proportion to the rate at which pheromones are released. We also show that pheromone clouds are affected by - but still quite robust to - turbulence, with the encounter cross section declining with the turbulent dissipation rate raised to a power of $1 / 2$. The sensitivity of mate encounter rates to turbulence is similar among copepods that produce pheromone trails and pheromone clouds.
\end{abstract}

KEY WORDS: Courting behaviour $\cdot$ Chemical signals $\cdot$ Sensitivity to turbulence $\cdot$ Scaling properties

\section{INTRODUCTION}

Mating is an important event in the life cycle of any sexually reproducing species as it has implications for the propagation of the individual and for the growth of the population. Finding mates at a sufficiently high rate to allow maintenance of the population is, obviously, critical. Mate finding may be particularly challenging in planktonic organisms, including pelagic copepods, since they live in a 3D, dilute environment, where the distance to the nearest potential mate may be significant and where random encounters would be insufficient to maintain the population (Buskey 1998). Various adaptations for increasing mate encounter rates have been described for pelagic copepods, including gathering of ready-to-mate adults at certain depth strata (Hayward 1981, Tsuda \& Miller 1998) and formation of mating swarms (Ambler et al. 1996). A more general feature of pelagic copepods is, however, their ability to locate remote mates, thereby enhancing their chances of encountering a sex partner. Some species seem to depend on hydromechanical cues for the location of mates (Strickler 1998, Bagøien \& Kiørboe $2005 \mathrm{~b}$, this volume), but in the majority of species examined so far chemical signalling appears to be involved: the female releases a pheromone that may be perceived by the male and helps him identify and locate her (e.g. Katona 1973). In one group of species 
the functioning of the pheromone signal can readily be deduced from the behaviour of the male. When encountering the trail of a swimming female, a characteristic tracking behaviour is elicited in the male in which he faithfully follows her trail at high speed while constantly reorienting so as to remain within the narrow borders of the invisible trail deposited by the female (Weissburg et al. 1998). Thus, in such species, the swimming female lays out a long and slender pheromone trail that efficiently leads the male to her. This kind of mate finding behaviour applies to species like Calanus marshallae (Tsuda \& Miller 1998), Temora longicornis (Doall et al. 1998), and Centropages typicus (Bagøien \& Kiørboe 2005a, this volume). The pheromone trail can be quite accurately modelled based on a mechanistic understanding of its functioning (Bagøien \& Kiørboe 2005a, Yen et al. 1998), and this has made it possible to estimate mate encounter rates, even in species for which we have only fragmentary information on their mate signal characteristics (Kiørboe \& Bagøien 2005).

In other species the spatial distribution of the chemical signal is less clear and the behaviour of the male in the vicinity of females much more difficult to interpret. Griffiths \& Frost (1976), for example, describe how Pseudocalanus sp. males engage in rapid zigzag swimming and figure-8 loops in the presence of females or in water conditioned by females and demonstrate that this behaviour is triggered by a chemical substance released by the female. This behaviour appears to be very different from the trail-tracking behaviour described for other species (cf. above), and it is unclear both what the exact functioning of the behaviour is and whether or how this chemically stimulated behaviour facilitates mate finding. Similar descriptions, i.e. female-elicited behaviour but absence of clear trail following, have been given for other species, e.g. Leptodiaptomus ashlandi (Nihongi et al. 2004) and possibly Eurytemora affinis (Katona 1973) and Oithona davisae (Uchima \& Murano 1988). Without a mechanistic understanding of signal generation and distribution it becomes difficult to evaluate the efficiency of the signal and, specifically, to estimate mate encounter rates.

The purpose of this study is to achieve a mechanistic understanding of this alternative way of transmitting chemical information. We examine the mate recognition behaviour of Pseudocalanus elongatus in detail by employing 3D video analysis. We use the behaviour of the males to delineate the extension of the chemical signal and behaviour of the females to assess how the signal is generated. We develop a simple model of signal extension based on how chemicals are dispersed by diffusion and advection and demonstrate that females of $P$. elongatus produce a short and spatially patchy pheromone cloud, rather than a long pheromone trail as found in other species. The model allows us to generalise our findings and to compare various features of this alternative way of chemical mate signalling, such as encounter cross section, scaling, and susceptibility to turbulence, with those of pheromone trails. In a subsequent paper we utilise this insight to estimate mate encounter rates and to examine population dynamical implications (Kiørboe \& Bagøien 2005).

\section{MATERIALS AND METHODS}

Pseudocalanus elongatus was collected from the North Sea and established in a continuous laboratory culture at $\sim 14^{\circ} \mathrm{C}$. The copepods were fed a mixture of phytoplankton, Rhodomonas baltica, Thalassiosira weissflogii, and Heterocapsa triqueta. New cohorts were established by removing all copepodites through sieving. Only recently matured individuals were used for experiments.

Then, 1 to $4 \mathrm{~d}$ prior to an experiment, 20 to 30 individuals of each sex (females without spermatophores and egg sac) were collected from the culture and kept separately until use. The animals were fed Rhodomonas baltica during this sex-deprivation period as well as during the experiments. At the start of an experiment, the males and females were added to a $10 \times 10 \times 10 \mathrm{~cm}^{3}$ aquarium, and their swimming and mate finding behaviour was recorded in the dark during $4 \mathrm{~h}$, as described below. We conducted 6 such experiments and identified 21 mate encounter events. In additional experiments, male swimming behaviour in the absence of females was recorded in water that had been preincubated for $2 \mathrm{~d}$ with females at 6 different concentrations between 0 and 12.5 ind. $1^{-1}$. Finally, in one experiment, 8 females were caged in a cylindrical $290 \mu \mathrm{m}$ plankton net cage (diameter $=0.9 \mathrm{~cm}$, height $=0.5 \mathrm{~cm}$ ) that was suspended in the aquarium. The swimming behaviour of ca. 20 males in the surrounding water was recorded for $2 \mathrm{~h}$. Swimming behaviour of the same males in the presence of an empty cage served as control.

Video recording and analysis was conducted as described by Bagøien \& Kiørboe (2005a). Briefly, 2 orthogonally mounted and synchronised CCD cameras equipped with $50 \mathrm{~mm}$ lenses simultaneously viewed the aquarium from the side. The aquarium was illuminated by collimated light from 2 infrared-light emitting diodes, one directed towards each camera, providing shadow images of the moving copepods. Each camera was connected to a VCR via a time code generator. Selected sections of the videos were captured $(25 \mathrm{~Hz})$ as AVI movies. 2D projections of copepod swimming tracks, using only 1 camera, were digitised automatically using LabTrack software (DiMedia), while 3D swimming tracks were analysed using ImageJ software 

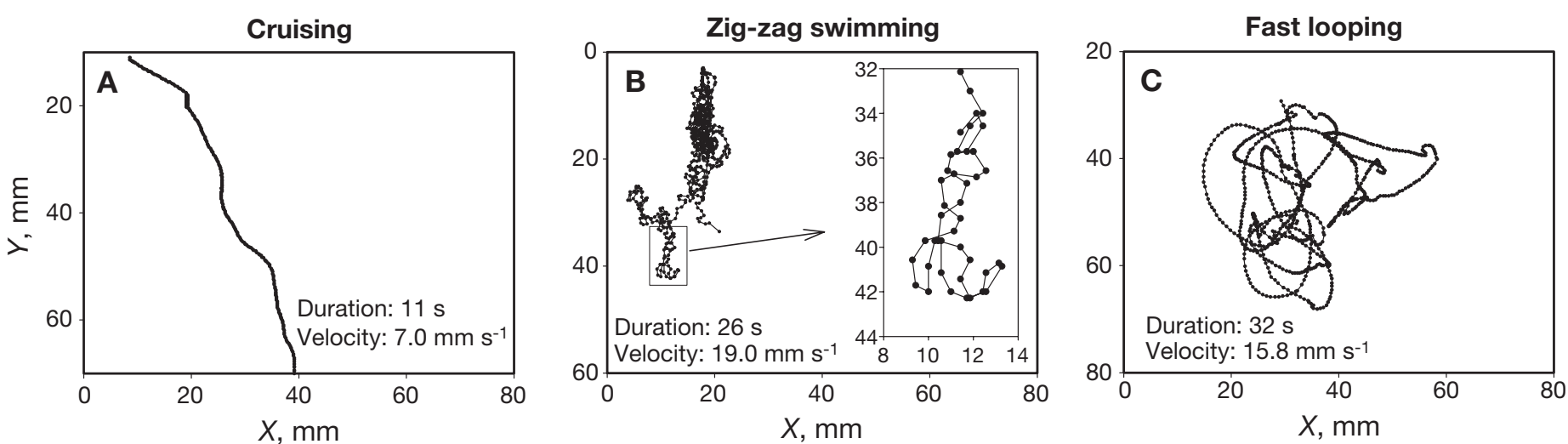

Fig. 1. Pseudocalanus elongatus. 2D projections of typical swimming tracks of (A) a cruising male and (B) a male in excited zigzag swimming or $(\mathrm{C})$ fast looping. The $x$ - and $y$-axes represent the horizontal and vertical, respectively

by combining pictures from the 2 cameras. These latter data, yielding $x, y, z$ positions of target males and females, were used to compute swimming velocities, mate distances, etc., as well as to generate 3D animations of swimming tracks to facilitate interpretation of observations.

Additional close-up videos of the swimming behaviour of Pseudocalanus elongatus were recorded with females swimming in a $10 \mathrm{~cm}$ diameter and $15 \mathrm{~cm}$ deep scaled-down version of Hamner's (1990) 'planktonkreisel' illuminated with white, fluorescent light. We used a CCD camera equipped with a $105 \mathrm{~mm}$ macro lens; individual females were followed for up to $1 \mathrm{~min}$ at a time by constantly adjusting the focus of the camera. These recordings were used to estimate the frequency at which females change body orientation.

\section{RESULTS}

Pseudocalanus elongatus females swam very slowly $\left(0.12 \pm 0.06 \mathrm{~cm} \mathrm{~s}^{-1}\right.$ mean $\left.\pm \mathrm{SD}\right)$ through the water or remained almost stationary (hovering). They often oriented themselves so that their head was directed upwards and their along-body axis tilted at $\sim 45^{\circ}$ relative to the vertical, hence with the feeding current mainly directed downwards. The females frequently changed their body orientation (tumbled). The head remained directed upwards, and the body orientation maintained a $\sim 45^{\circ}$ tilt relative to the vertical, with the feeding current directed all the while primarily downwards. In 8 females that were studied closely during 29 to $73 \mathrm{~s}$, tumbling frequency varied between 0.06 and $0.29 \mathrm{~s}^{-1}$, with an overall mean of $0.16 \pm 0.09 \mathrm{~s}^{-1}$. Some stationary females, in addition to reorienting as described above, displayed smaller changes in tilt (body orientation changing only $\left.\sim 10^{\circ}\right)$ and at a higher frequency $\left(1 \mathrm{~s}^{-1}\right)$. The constant reorientation and small movements made the female motility resemble a 'random walk', which can be characterised by an equivalent diffusion coefficient of about $10^{-2} \mathrm{~cm}^{2} \mathrm{~s}^{-1}$ (Kiørboe \& Bagøien 2005). There was no difference in the female motility pattern in the absence and presence of males.

In the absence of females, males either remained more or less inactive or cruised through the water at velocities substantially greater than those of the females $\left(0.6 \pm 0.3 \mathrm{~cm} \mathrm{~s}^{-1}\right)$ and with a higher degree of directional persistence (Fig. 1a). In the presence of females, some males engaged in a very different and 'excited' mode of swimming (Fig. 1b,c) that could last for many minutes. The swimming velocity during such periods was high, averaging about $2 \mathrm{~cm} \mathrm{~s}^{-1}$, and the swimming pattern alternated between rapid zigzag swimming (Fig. 1b) and fast looping (Fig. 1c). Sometimes this swimming behaviour was initiated without any obvious triggering stimulus ('decoupled courtship'), but often it was directed towards a particular female (Fig. 2). In the latter

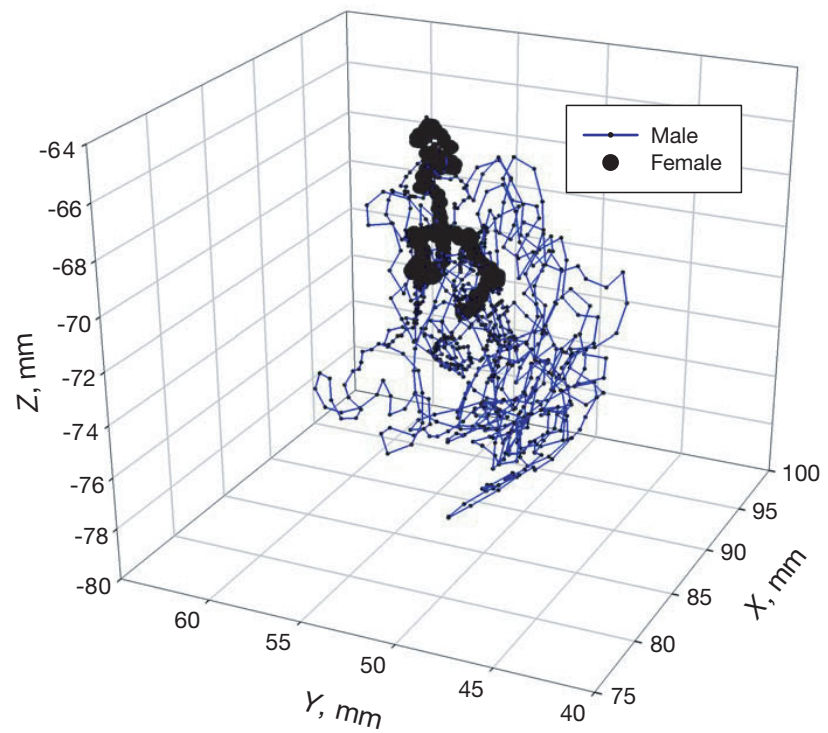

Fig. 2. Pseudocalanus elongatus. Male and female swimming tracks of a 40 s section of a prolonged courtship 

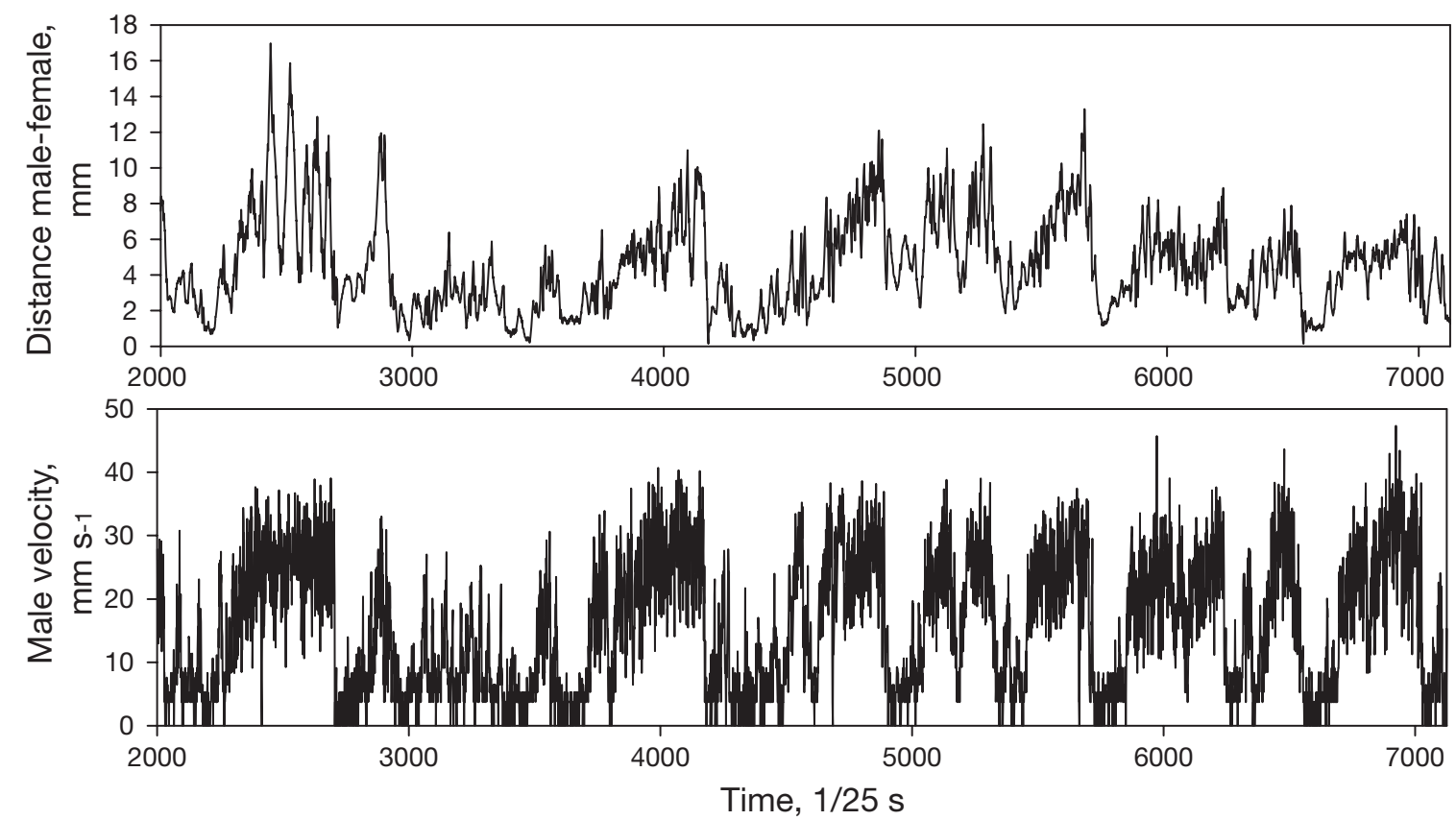

Fig. 3. Pseudocalanus elongatus. Temporal variation in the distance between the 2 mates (upper panel) and swimming velocity of the male during a 200 s section of a courtship

case, the male displayed a complicated behaviour reminiscent of 'courtship', where he would speed around the female in zigzags and loops for a long time (minutes) while coming up to touch her every 10 to $20 \mathrm{~s}$. This cycle of events could be repeated many times. One digitised case lasted for at least $5 \mathrm{~min}$ (Fig. 3), and others were of even longer duration. While in the vicinity of the female, the male slowed down or even stopped completely, often touching and pushing the female, whereas between encounters he swam rapidly, up to $4 \mathrm{~cm} \mathrm{~s}^{-1}$, and made long journeys that could bring him up to $15 \mathrm{~mm}$ away from her. The velocity of the male during these pursuits thus increased with the distance to the female (Fig. 4). The female most often remained calm during visits and physical contact but at times performed short escape jumps away from the approaching male. We assume that the male attached a spermatophore to the female during one such visit, but we were unable to actually see this at the low magnification at which the observations were recorded.

Despite the long excursions, the male always managed to return to the female. There is apparently a relatively wide region around the female where the male is aware of her presence and within which he is capable of navigating back to her. The swimming trails and positions of the males relative to the females during this courtship behaviour define the extent and dimensions of this volume (Fig. 5). The vertical direction in this plot is defined as the swimming direction of the female as averaged over 8 video frames $(=8 / 25 \mathrm{~s})$.
However, because the swimming direction is poorly defined in these 'diffusing' females, the apparent distribution of male positions around the female becomes somewhat smeared. Direct video observations and, in particular, 3D animations of swimming trails suggest that the distribution of male positions relative to the female is more biased 'downstream' from the female than actually suggested in Fig. 5. A video clip and a 3D animation of an example pursuit is available as an Electronic Supplement (www.int-res.com/ articles/suppl/blind_dating/).

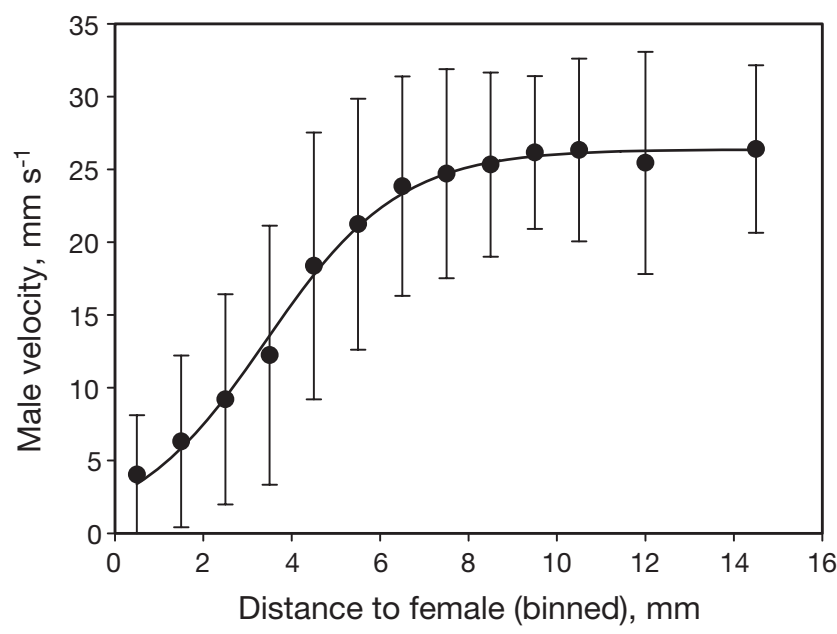

Fig. 4. Pseudocalanus elongatus. Relation between male swimming velocity and distance to the female during courtship 


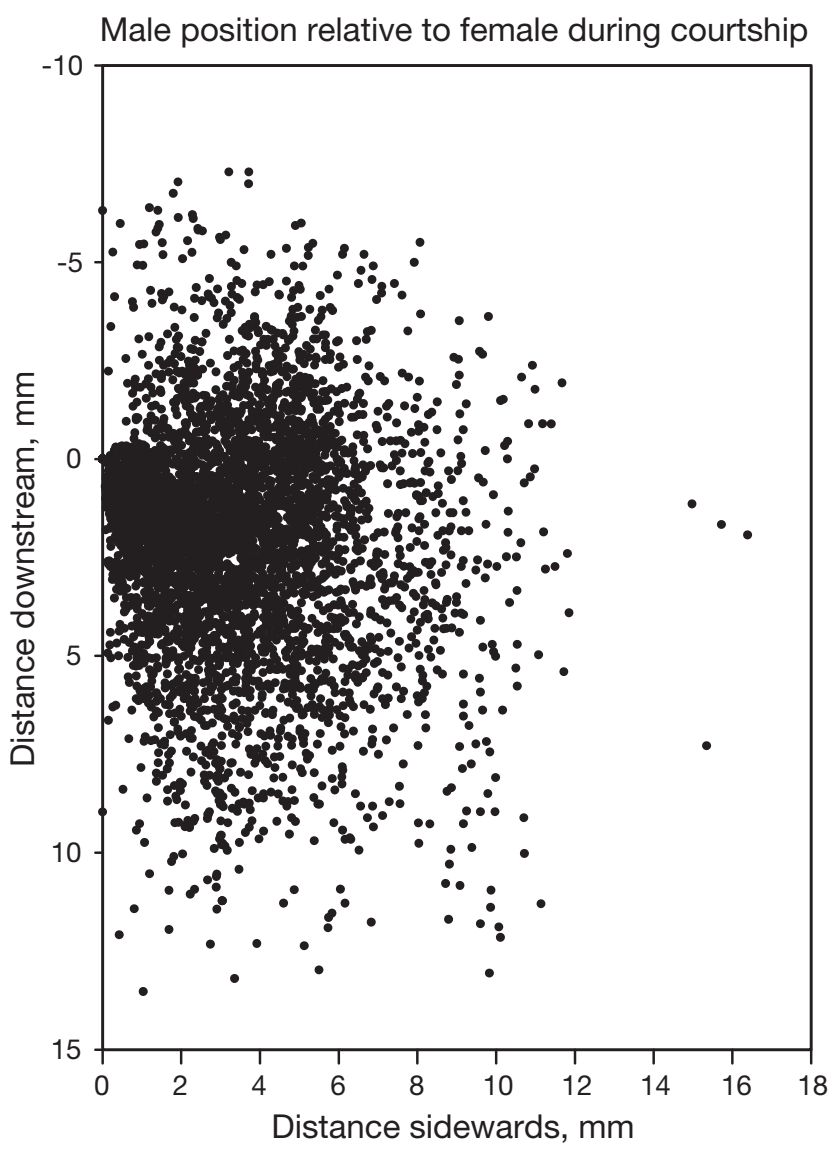

Fig. 5. Pseudocalanus elongatus. Instantaneous positions of the male relative to the female during courtship $(\mathrm{n}=\mathrm{ca} .5000)$. The vertical axis represents the swimming direction of the female. All positions observed in 3 dimensions are folded onto this plane such that all distances and angles are correct

Males swimming in female-conditioned water (up to 12.5 females $\mathrm{l}^{-1}$ ) did not show excited swimming behaviour (zigzag or rapid loops) during periods of $0.5 \mathrm{~h}$ of observation, whereas caged females triggered this type of behaviour. Thus, the signal that elicits courtship behaviour is obviously chemical in nature, i.e. a pheromone, even though clear trail tracking behaviour was never observed.

\section{DISCUSSION}

\section{Courtship behaviour}

The excited swimming behaviour of Pseudocalanus elongatus males that we observed in the presence of females, with rapid zigzag and loop swimming, is consistent with the description provided by Griffiths \& Frost (1976). We demonstrate here, in addition, that this behaviour is often directed towards a specific female and that the entire courtship in this case takes place within a relatively restricted volume around the female. Caged females were able to signal their presence to males swimming in the surrounding water, and we thus confirm the results of Griffiths \& Frost (1976) who demonstrated that the courtship behaviour is elicited by a chemical signal-a pheromone-produced by the female. Unlike Griffiths \& Frost (1976), we were unable to stimulate excited swimming in males by exposing them to female conditioned water. However, the highest concentration of females that we used ( 1 ind. per $80 \mathrm{ml}$ ) was much lower than that of Griffiths \& Frost (1 ind. per $2 \mathrm{ml}$ ). This would suggest that the volume of water that is influenced by female pheromones is $<80 \mathrm{ml}$ but $>2 \mathrm{ml}$.

The excited swimming behaviour of male Pseudocalanus elongatus is radically different from the trail tracking behaviour observed in males of species where the female produces a pheromone trail. Trail tracking, as described for Temora longicornis, Calanus marshallae, and Centropages typicus, is typically of short duration, a few seconds, and leads the male directly to the female, where mating immediately takes place or is attempted (Doall et al. 1998, Tsuda \& Miller 1998, Bagøien \& Kiørboe 2005a). During trail tracking, the male swims in a manner somewhat similar to the zigzag swimming described here for the males of $P$. elongatus, i.e. constantly reorienting the body, but the overall direction of male movement is along the trail that leads to the female. In P. elongatus, in contrast, the duration of the mate chase is long, and the swimming direction of the male is not consistently towards the female. Also, the male does not seem to complete his mission when first encountering the female but continues to swim in her vicinity while paying occasional visits. Based on the behaviour of the male we suggest that the female of $P$. elongatus is surrounded by a rather diffuse, near-spherical cloud of pheromones. We assume that the 'uncoupled courtship', where excited male swimming occurs independently of any particular female, although only in the presence of females, is a laboratory artefact. Due to the artificially high female concentration in the experimental aquarium, puffs of pheromone from several females may drift around in the aquarium and confuse males, thus eliciting uncoupled courtship behaviour.

Thus, we do not consider the excited swimming mode in the males as a mate-finding behaviour. The excited swimming is only elicited once a pheromone cloud has been encountered, and at that point the male has in some sense already almost found the female. We rather consider the excited swimming as part of a courtship behaviour - of unknown function-and as a mechanism whereby the male can remain inside the pheromone cloud and near the female. This is not to say that the pheromone cloud does not serve the pur- 
pose of enhancing mate finding efficiency. On the contrary, the pheromone cloud expands the encounter cross section of the female considerably and thus enhances the probability that a cruising male will find a receptive female.

Other species may also produce more diffuse pheromone clouds. Thus, Weissburg et al. (1998) suggested, again based on behaviour of the males, that females of Temora longicornis produce a more diffuse pheromone plume when hovering, in contrast to the distinct pheromone trail produced by cruising females. They ascribed these differing shapes of the pheromone plumes to the broad downstream current produced by a hovering female, unlike the much narrower stream of a cruising female. A similar suggestion was offered by Nihongi et al. (2004) to explain the mate finding behaviour observed in the freshwater copepod Leptodiaptomus ashlandi. Females of $L$. ashlandi are, like those of $P$. elongatus, mainly hovering and thus produce a relatively broad downstream feeding current. While it has been possible to describe the pheromone trails produced by some species quite precisely (Yen et al. 1998, Bagøien \& Kiørboe 2005a), a more exact characterisation of the more diffuse pheromone clouds produced by other species has so far not been attempted. Such a characterisation is important for a more precise evaluation of the significance of the plume in enhancing mate encounter rates. P. elongatus offers a particularly good possibility for doing so, since the male during his long-lasting display paints a rather precise picture of the pheromone cloud. Below, through a modelling exercise, we attempt to describe the pheromone plume, to estimate its encounter cross section, and to compare the characteristics of pheromone clouds with those of pheromone trails.

\section{Plume characteristics}

Bagøien \& Kiørboe (2005a) used the 'moving point source model' to describe and explore the characteristics of pheromone trails, but obviously this description does not apply to Pseudocalanus elongatus and other species with an apparently more cloud-like distribution of pheromones. Pheromones are spread from the female by advection and diffusion. To describe the distribution of pheromones released by a female one first needs to know the fluid flow field around the female to subsequently solve the advection-diffusion equation. The most striking and consistent difference in female behaviour among species that produce pheromone clouds and those that generate trails is that the latter cruise or sink through the water, while the former move very little: $P$. elongatus females are almost tethered by gravity (hovering) while the beat- ing appendages move water past the animal. We will describe the hovering copepod as a force applied in the water at a stationary point (a 'Stokeslet'; Tiselius \& Jonsson 1990) where pheromones are also released. This model is also consistent with the suggestion of Weissburg et al. (1998) and Nihongi et al. (2004).

The flow velocity generated by a Stokeslet is (in polar coordinates, $r, \theta$ ) (Batchelor 1967, Visser 2001):

$$
\begin{aligned}
& u_{r}=\frac{3}{2} \frac{a U}{r} \cos \theta \\
& u_{\theta}=-\frac{3}{4} \frac{a U}{r} \sin \theta
\end{aligned}
$$

where $a$ is the spherical radius of the copepod, $U$ is its sinking velocity in the absence of the feeding current, and $u_{r}$ and $u_{\theta}$ are the radial and azimuthal components of the flow velocity, respectively. If pheromones of diffusivity $D_{P}$ are released at the same point as where the force is applied and at a rate $Q$, then the steady-state concentration field is given by (Thygesen \& Kiørboe unpubl.):

$C_{r, \theta}=\frac{Q \mathrm{e}^{[-1 / 2 P e(1-\cos \theta)]} P e}{4 \pi D_{p} r\left(\mathrm{e}^{P e} P e-\mathrm{e}^{P e}+P e+1\right) \mathrm{e}^{-P e}} \approx \frac{Q}{4 \pi D_{p} r} \mathrm{e}^{[-1 / 2 P e(1-\cos \theta)]}$

where e is the exponential function, and $P e=3 / 2 \times$ $U a / D_{P}$ is the Peclet number. Note that for $U=0$, the exponential term becomes equal to 1 and the equation becomes identical to the classical solution for a nonmoving point source (which it should) (e.g. Denny 1993). The approximation is valid for $P e \gg 1$ and $P e \ll$ 1 , which is true in most cases. Exactly on the alongbody axis downstream (behind) the copepod $(\theta=0)$, the expression for $C$ becomes identical to the solution for both a moving and a non-moving point source:

$$
C_{z}=\frac{Q}{4 \pi D_{p} Z}
$$

where $z$ is the downstream distance behind the copepod. If we assume that there is a threshold concentration for detection, $C^{*}$, it follows from Eq. (3) that the extension of the detectable plume in the downstream direction, $L$, is:

$$
L=\frac{Q}{4 \pi D_{p} C^{*}}
$$

We know some of the parameters that enter Eq. (2) (i.e. size and sinking velocity), and we can provide good estimates of the others (Table 1). Hence, we can evaluate the extension of the model plume. Bagøien \& Kiørboe (2005a) argued that diffusible pheromones should be small molecules, e.g. amino acids, with diffusion coefficients of about $10^{-5} \mathrm{~cm}^{2} \mathrm{~s}^{-1}$. We cannot directly estimate the rate of pheromone production $(Q)$ or the pheromone sensitivity $\left(C^{*}\right)$, but we can assess their ratio, $Q / C^{*}$, which is sufficient for drawing the 
Table 1. Variables and default parameter values. All values apply to Pseudocalanus elongatus

\begin{tabular}{|c|c|c|c|c|}
\hline Symbol & Meaning & Dimensions & Default value & Source \\
\hline a & Equivalent spherical radius of female & $\mathrm{cm}$ & 0.03 & Kiørboe et al. 1999 \\
\hline$b$ & Length of male antennules & $\mathrm{cm}$ & 0.1 & \\
\hline$C^{*}$ & Pheromone threshold sensitivity & $\mathrm{mol} \mathrm{cm}{ }^{-3}$ & - & \\
\hline Q & Pheromone production rate & $\mathrm{mol} \mathrm{s}^{-1}$ & - & \\
\hline$Q / C^{*}$ & $\begin{array}{l}\text { Ratio of pheromone production rate to } \\
\text { pheromone sensitivity }\end{array}$ & $\mathrm{cm}^{3} \mathrm{~s}^{-1}$ & $10^{-3}$ & $\begin{array}{l}\text { Extrapolated from observations } \\
\text { reported in Bagøien \& Kiørboe (2005a) }\end{array}$ \\
\hline$D_{P}$ & Diffusion coefficient of pheromone & $\mathrm{cm}^{2} \mathrm{~s}^{-1}$ & $10^{-5}$ & Bagøien \& Kiørboe (2005a) \\
\hline$D_{F}$ & Equivalent diffusion coefficient of female & $\mathrm{cm} \mathrm{s}^{-2}$ & $10^{-2}$ & Kiørboe \& Bagøien (2005) \\
\hline$L$ & Length of pheromone trail & $\mathrm{cm}$ & & \\
\hline 1 & Equivalent encounter cross section radius & $\mathrm{cm}$ & & \\
\hline \multirow[t]{3}{*}{$U$} & Sinking velocity of non-swimming female & $\mathrm{cm} \mathrm{s}^{-1}$ & 0.11 & Tiselius \& Jonsson 1990 \\
\hline & Tumble rate & $\mathrm{s}^{-1}$ & 0.16 & This study \\
\hline & Tumble angle & rad & $\pi / 4$ & This study \\
\hline
\end{tabular}

plume. Here we make use of the fact that Eq. (4) also applies to copepods that produce pheromone trails ('moving point source', Bagøien \& Kiørboe 2005a). Estimates of $Q / C^{*}$ for such species can be obtained from measurements of the length of the trails and by assuming a pheromone diffusivity, $D_{P}$, of $10^{-5} \mathrm{~cm}^{2} \mathrm{~s}^{-1}$. Estimates of $Q / C^{*}$ from observed trail lengths in the 3 species in Bagøien \& Kiørboe (2005a) increase with female size, presumably because large copepods produce pheromones at a higher rate than small copepods. Assuming that Pseudocalanus elongatus has a similar pheromone sensitivity and pheromone production rate as trail-tracking copepods, then the observations reported in Bagøien \& Kiørboe (2005a), extrapolated to the size of $P$. elongatus females, yield $Q / C^{*} \sim 10^{-3} \mathrm{~cm}^{3} \mathrm{~s}^{-1}$.

Using these numbers, the model for the hovering copepod produces a much broader pheromone plume than the model for the cruising copepod, which is in accordance with intuition (Fig. 6). The encounter cross section, estimated numerically as the average of the trans-sectional area of the plume when viewed from many different random directions, is $2.9 \mathrm{~cm}^{2}$ for a point-sized male or $7.7 \mathrm{~cm}^{2}$ for a male with a sensor radius (antennule length) of $0.1 \mathrm{~cm}$. This corresponds to an equivalent spherical volume of 4 to $16 \mathrm{ml}$. However, the predicted plume for the hovering copepod is much more elongated than expected and far from the short cloud-like plume suggested by male behaviour (Fig. 5). Also, the anticipated plume length estimated from Eq. (4) is $8 \mathrm{~cm}$, which is very different from the observed male reaction distance of 1 to $2 \mathrm{~cm}$ from the female. $P$. elongatus males are particularly well equipped with chemosensory aesthetascs on the antennules (Griffiths \& Frost 1976, Ohtsuka \& Huys 2001), and they may be more sensitive to pheromones than other species, but that would lead to an even longer predicted plume length.

However, in describing the hovering copepod we have ignored the fact that the female moves slightly and tumbles frequently. This way her pheromones are spread in constantly shifting directions and from constantly shifting positions, thus generating a cloud rather than a trail. We can take this into account by considering the motility of female Pseudocalanus elongatus as a random walk with an equivalent diffusion

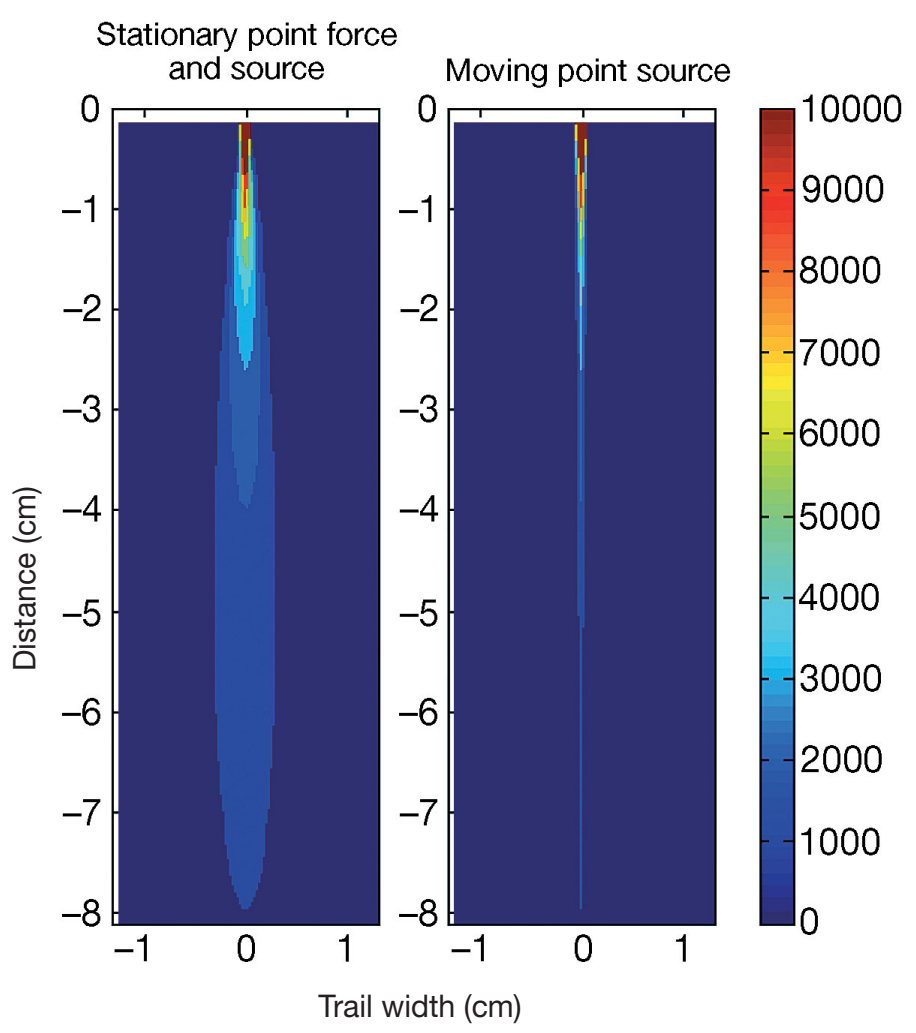

Fig. 6. Extension of pheromone plume around a hovering copepod (left panel) and behind a cruising copepod (right panel) computed from Eq. (2) and from the moving point source model (Bagøien \& Kiørboe 2005a), respectively, using values typical for Pseudocalanus elongatus females (Table 1). For the cruising copepod, a swimming velocity similar to the sinking velocity of a non-moving copepod is assumed. Contour levels are values of $C / Q$ in units of $\mathrm{s} \mathrm{cm}^{-3}$ 
coefficient, $D_{F \prime}$ of $10^{-2} \mathrm{~cm}^{2} \mathrm{~s}^{-1}$ (Kiørboe \& Bagøien 2005). Then, rather than considering only the diffusivity of the pheromone molecules, we must also consider the (much larger) diffusivity of the point source (the female) and replace the molecular diffusivity in Eqs. (2) to (4) with the sum of molecular and female diffusivities, $D_{P}+D_{F} \sim D_{F}$, since $D_{F} \gg D_{P}$. Using characteristic values for $P$. elongatus (Table 1) the predicted average concentration field becomes almost spherical and similar to that suggested by male behaviour (Fig. 7). However, the predicted extension of the pheromone plume in the downstream direction is now only $8 \times 10^{-3} \mathrm{~cm}$, once again very different from what our observations would suggest and in fact less than the size of the female. The encounter cross section is small $\left(2 \times 10^{-4} \mathrm{~cm}^{2}\right)$, also for a finite-sized male $(4 \times$ $10^{-2} \mathrm{~cm}^{2}$ ). Even if males of $P$. elongatus are 10 times more sensitive than trail-tracking copepods (10 times lower $C^{*}$ ), the predicted reaction distance would still be less than $0.1 \mathrm{~cm}$, which is at least an order of magnitude less than the observed reaction distance.

Eq. (2) describes the average pheromone concentration. Since pheromones are spread mainly by the small-scale dancing of the female, the average concentration is different from the instantaneous concentration at any moment in time and different from what a passing male experiences. To examine the instantaneous distribution pattern of pheromones, we employ numerical simulation. We use the same description of the fluid flow field relative to the female as above, but in a fixed coordinate system we let it change over time, either by having the female move around in a random 'diffusive' manner or by letting the female change her body orientation and thus the direction of her feeding current at a certain average tumbling frequency. From the resulting complex flow field we solve the advection-diffusion equation numerically. Further details are given in Appendix 1.

The resulting predicted pheromone plume, defined as the regions within which pheromone concentration exceeds $C^{*}$, is a spatially patchy structure, regardless of whether the female is performing a random walk or reorienting frequently (Fig. 8). The actual plume structure will change constantly, depending at any time on the recent motions of the female. However, some essential features of the plume, such as its patchiness, its spatial extension, and its encounter cross section, will remain approximately constant. The spatial extension of the predicted plumes are largely consistent with the observed male behaviour, i.e. near spherical and with linear dimensions on the order of 1 to $2 \mathrm{~cm}$. One can imagine that a male swimming inside the spatially patchy plume region may experience temporal gaps in signal perception, but that his travelling at high speed along a convoluted zigzag path would allow almost constant contact between the male and the signal, enabling him to remain within the plume region despite its patchiness.

Because the pheromone concentrations within the plume are heterogeneous, a cruising male when first entering the plume region may not necessarily encounter pheromone concentrations sufficiently high to elicit the excited swimming behaviour, and thus he may not immediately perceive the vicinity of the female. The probability of this happening depends on the patchiness of the plume as well as on the size of the

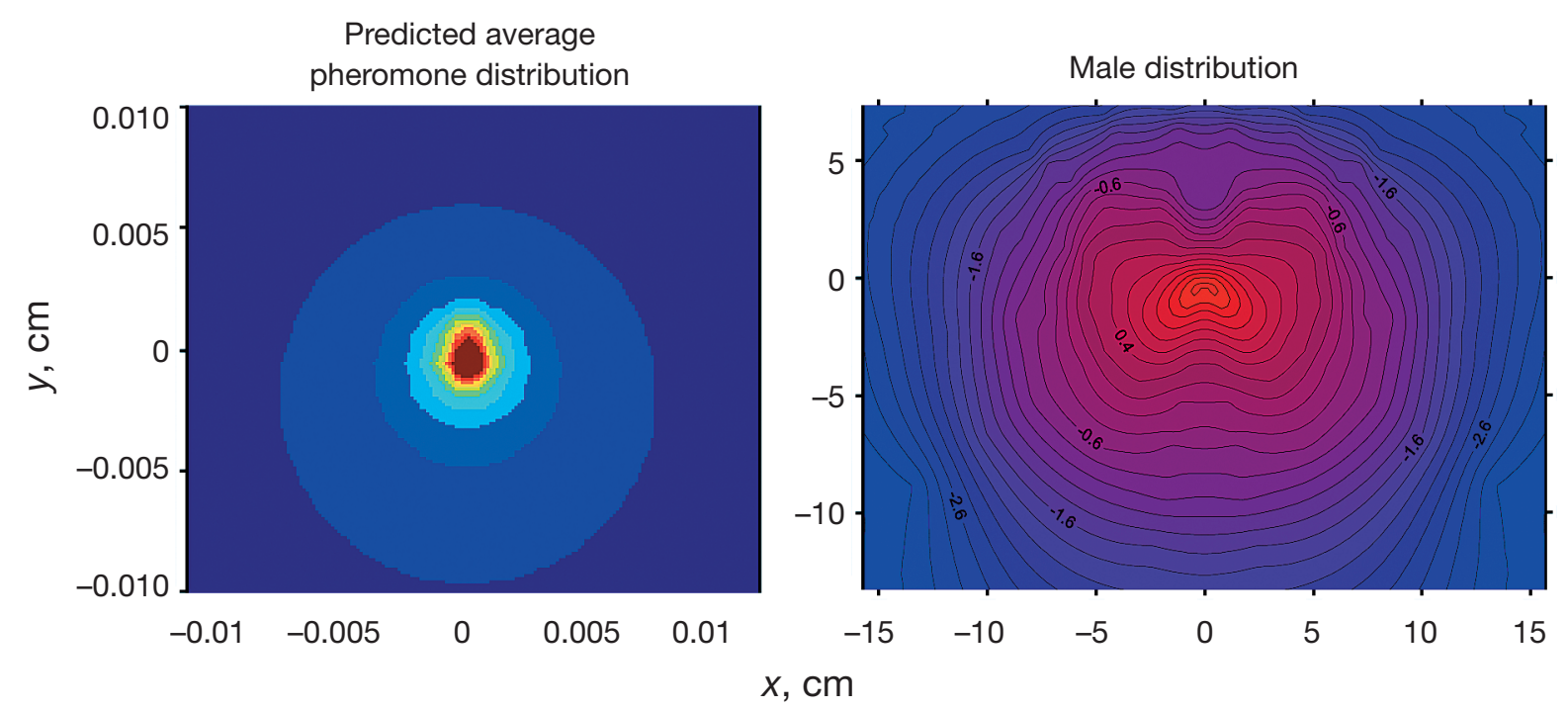

Fig. 7. Pseudocalanus elongatus. Predicted average concentration of pheromones around a diffusing female computed from Eq. (2) using a female diffusivity of $10^{-2} \mathrm{~cm}^{2} \mathrm{~s}^{-1}$ (left panel) and contour plot of log concentration of male positions relative to the female (right panel). The position observations in Fig. 5 have been converted to volume concentrations, taking the spherical geometry into consideration. The $x$ - and $y$-axes represent the horizontal and vertical, respectively 

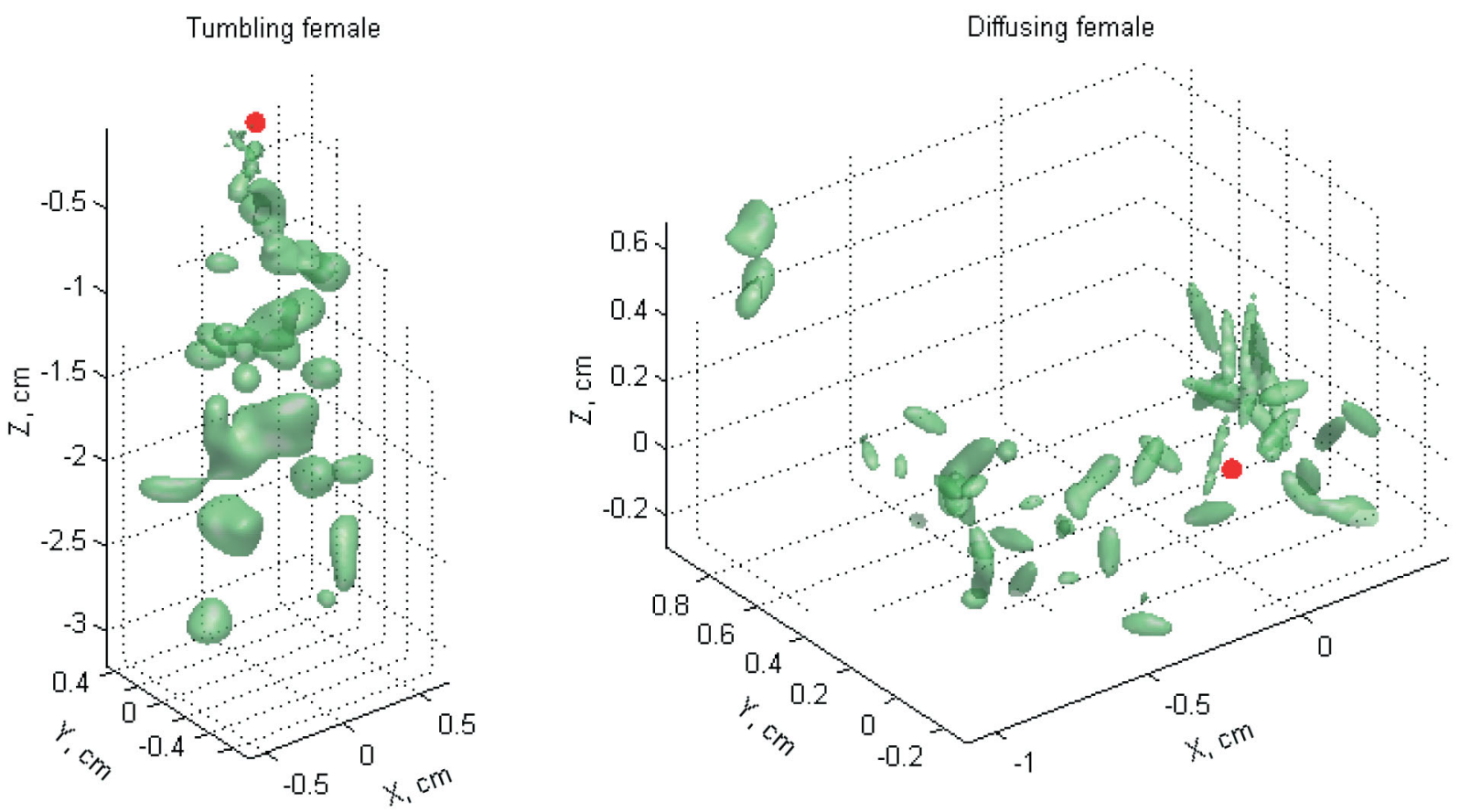

Fig. 8. Patchy plumes generated by a 'tumbling' (left panel) and a 'diffusing' female (right panel), computed by simulation analysis using default parameters (Table 1). The plume is defined as the region within which the pheromone concentration exceeds $C^{*}$, i.e. $C^{*} / Q<10^{3} \mathrm{~s} \mathrm{~cm}^{-3}$

copepod (essentially: length of the antennules). We may estimate the average encounter cross section as seen by a finite-sized copepod as above-i.e. view the plume from many different directions and average the cross-section areas. The resulting areas for the 2 situations in Fig. 8 are 1.4 and $2.5 \mathrm{~cm}^{2}$, corresponding to the cross section of a sphere of radius 0.6 to $0.9 \mathrm{~cm}$ and volume 1 to $3 \mathrm{ml}$. This may be a conservative estimate since $P$. elongatus males may be more responsive to pheromones than the average copepod, cf. above.

The encounter cross section of the patchy plume (Fig. 8) is much larger than the cross section of the average plume (Fig. 7). However, it is substantially lower than for the plume generated by a stationary, pumping female. In fact, the estimated plume cross section decreases with increasing restlessness of the female (Fig. 9), and one may therefore ask why the female moves at all, as moving has an apparent cost in terms of the extension of the detectable plume. This has to do with the time scale of signal propagation, i.e. the time required to transport the signal to the end of the detectable plume. Pheromones are transported from the female by a combination of diffusion (molecular diffusion and diffusivity of the female) and advection. Because advection dominates the transport for the stationary, pumping copepod, we ignore molecular diffusion and ask how long it takes to transport a water particle a distance $L$ directly downstream by the feeding current. This time, $T$, can be estimated from Eq. (1) as:

$$
T=\int_{a}^{L} u_{r}^{-1} \mathrm{~d} r=\int_{a}^{L} \frac{2}{3} \frac{r}{a U} \mathrm{~d} r=\frac{L^{2}}{3 a U}
$$

Eq. (4) predicts, for a hovering, non-moving female, the plume extension in the downstream direction, $L$, to be $8 \mathrm{~cm}$ using default parameters $\left(U=0.11 \mathrm{~cm} \mathrm{~s}^{-1}\right.$, $a=0.03 \mathrm{~cm}$ ), which yields $T=6500 \mathrm{~s}$ (Eq. 5). Thus, it takes about $2 \mathrm{~h}$ to establish the plume, which is obviously an irrelevant time scale for the mate chase. At the other extreme, if the female moves constantly, pheromones are spread mainly by her diffusivity, and the time required to transport the solute over a distance $L$ is $T=L^{2} / D_{F}$. The downstream extension of the average plume (Fig. 8) was $8 \times 10^{-3} \mathrm{~cm}$ for $D_{F}=10^{-2}$ $\mathrm{cm}$, hence $T=6 \times 10^{-3} \mathrm{~s}$. That is, the plume is established almost instantaneously. There is thus a tradeoff here between low motility, large plume and long time scale on the one hand, and high motility, small plume and fast steady state on the other. This can be illustrated by how time scale and steady-state extension of the simulated plume both decline with, for example, the tumbling frequency (Fig. 9a,b). Likewise, the plume 'fills' faster with increasing motility of the female, although the final steady-state cross section diminishes (Fig. 9c). The diffusivity and tumbling frequency realised by Pseudocalanus elongatus females (Table 1) are such that the time to achieve steady state, 100 to $500 \mathrm{~s}$ (Fig. 9), is of the same order as the time scale of the mate pursuit, 1 to $10 \mathrm{~min}$, and $P$. elongatus has thus found the optimum trade-off. 

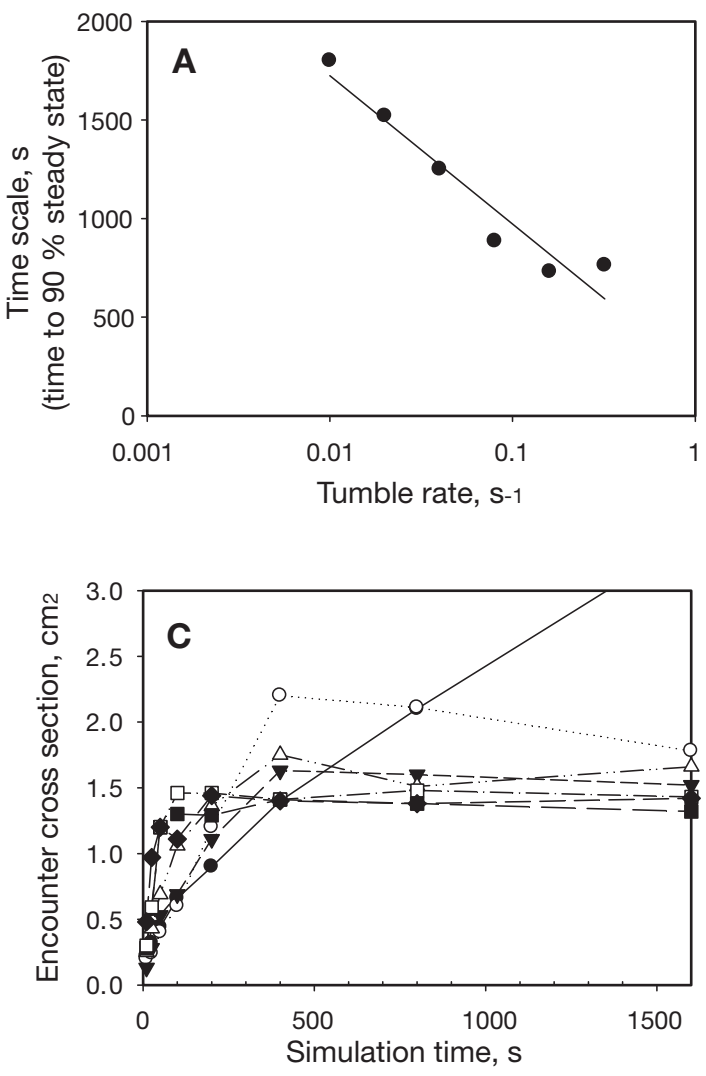

\section{Pheromone clouds vs. pheromone trails: susceptibility to turbulence}

A female must move to spread the pheromone signal in order to overcome the problem of slow transport by molecular diffusion. Different female behaviours lead to different structures of pheromone plumes - trails or clouds - which in turn lead to different male behaviours. There is nothing to suggest that one strategy is better than the other in terms of enhancing mate encounter rates (Kiørboe \& Bagøien 2005). However, chemical signals are susceptible to ambient fluid motion, and Visser \& Jackson (2004) have described how chemical trails, like the pheromone trails described for copepods, are eroded by turbulence. Fluid shear stretches the trail, makes it thinner and therefore more susceptible to molecular diffusion, and eventually breaks up the trail into shorter filaments. Turbulence also causes a pheromone trail to bend and wiggle, and at sufficiently high intensities the trail eventually becomes very folded and rolled up around the female. In fact, a pheromone trail eroded by turbulence may look very similar to the short spatially patchy pheromone clouds described in this paper. Since pheromone clouds may look like a turbulenceeroded pheromone trail, one might assume that trails are more susceptible to turbulence than clouds. This is,

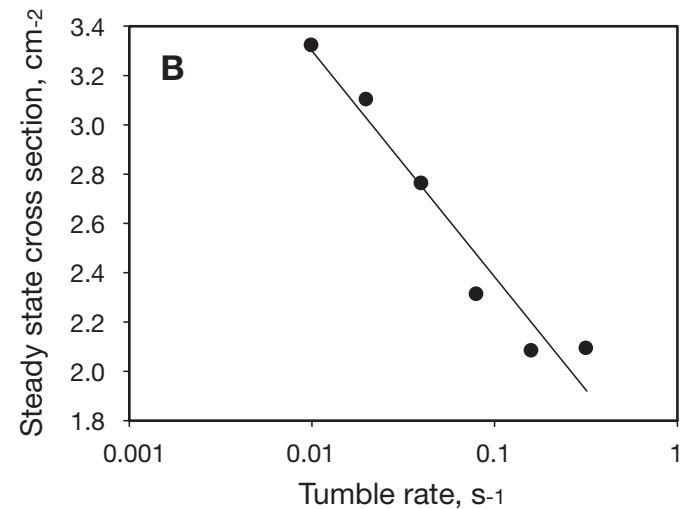

Female diffusivity

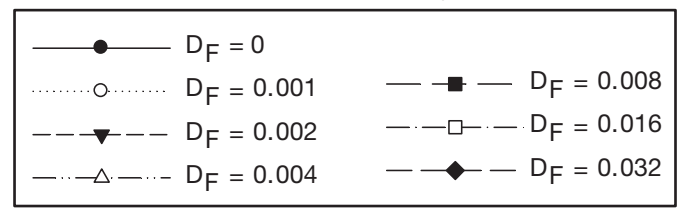

Fig. 9. Time and space scales of the simulated pheromone cloud. (A) Time to achieve $90 \%$ of the steady-state encounter cross section and (B) encounter cross section of the plume at steady state as a function of the tumbling frequency of the female. (C) Encounter cross section as a function of simulation time for varying female diffusivities. All parameters used in the simulation are default (Table 1), except for those that vary

however, not necessarily the case. Visser \& Jackson (2004) showed that chemical trails are robust to turbulence as long as $\gamma L / u<1$, where $\gamma$ is the along-trail shear rate, $L$ the trail length and $u$ the cruising velocity of the female. Because $\gamma=(\varepsilon / 6 \eta)^{1 / 2}$, where $\varepsilon$ is the turbulent dissipation rate and $\eta$ fluid viscosity $\left(\sim 10^{-2} \mathrm{~cm}^{2}\right.$ $\mathrm{s}^{-1}$ for seawater), it follows that one can define a critical dissipation rate, above which turbulent erosion of chemical trails become significant, as:

$$
\varepsilon_{\text {Critical,trail }}=6 \eta\left(\frac{u}{L}\right)^{2}
$$

For a cruising copepod female that deposits a pheromone trail, but with characteristics otherwise similar to Pseudocalanus elongatus, i.e. $u=0.11 \mathrm{~cm} \mathrm{~s}^{-1}$ and $L=8 \mathrm{~cm}$, the critical dissipation rate becomes $10^{-5} \mathrm{~cm}^{2} \mathrm{~s}^{-1}$. Because trail length is independent of swimming velocity (Bagøien \& Kiørboe 2005), and since susceptibility to turbulence decreases with increasing swimming velocity (Eq. 6), a high swimming velocity protects the signal against turbulence. This may be why typical trail producers similar to $P$. elongatus in size swim fast, about $0.5 \mathrm{~cm} \mathrm{~s}^{-1}$ (Doall et al. 1998, Bagøien \& Kiørboe 2005a).

For a cloud-generating Pseudocalanus elongatus, pheromones are spread mainly by the random motility of the female. For turbulence to become important, tur- 
bulent diffusivity at the scale of the pheromone plume, $K_{l}$, must exceed the equivalent diffusivity of the female, $D_{F}$, because according to Richardson's law $K_{l}=\varepsilon^{1 / 3} l^{4 / 3}$, we can again define a critical turbulent dissipation rate for pheromone clouds, above which turbulence becomes important in eroding the plume, i.e. when $D_{F}=K_{l}$, which implies:

$$
\varepsilon_{\text {Critical,cloud }}=\frac{D_{F}^{3}}{1^{4}}
$$

where $l$ is the length scale (radius) of the cloud. Again using values typical of $P$. elongatus, i.e. $D_{F}=10^{-2} \mathrm{~cm}^{2}$ $\mathrm{s}^{-1}$ and $l=0.8 \mathrm{~cm}$, yields a critical dissipation rate of $2 \times 10^{-6} \mathrm{~cm}^{2} \mathrm{~s}^{-1}$, i.e. slightly less than above. Thus, pheromone clouds appear to be no more resistant to turbulence than pheromone trails. However, as turbulence starts to erode a pheromone cloud or trail, the plume becomes smaller, i.e. $L$ or $l$ declines. The dependency of the critical dissipation rate on plume dimensions implies that the remaining plume becomes increasingly resistant to turbulence as it diminishes, and more rapidly so for clouds than for trails because of the different scaling, i.e. $L \infty \varepsilon^{-1 / 2}$ and $l \infty \varepsilon^{-1 / 4}$, respectively. In that sense, pheromone clouds may be more resistant to turbulence than pheromone trails. However, mate encounter rate scales with $L$ in copepods producing pheromone trails but with $l^{2}$ in those producing clouds (Kiørboe \& Bagøien 2005), and thus the above-mentioned advantage of the cloud producers is cancelled out when it comes to optimising mate encounter probabilities. Dissipation rates of the critical magnitude and higher are common in the upper mixed layer of the ocean (e.g. Kiørboe \& Saiz 1995), and turbulence may thus interfere with chemical mate communication in the upper ocean, and equally so for the 2 chemical signalling strategies. However, because pheromone signal dimensions are only weakly dependent on the critical dissipation rates (Eqs. 6 \& 7), pheromone signals are quite robust and will still be functional at even relatively high levels of turbulence.

In comparing pheromone trails and clouds we may finally examine how their dimensions scale with the size of the copepod producing them. Pheromone trails are mainly characterised by their length, which is directly proportional to the rate, $Q$, at which pheromones are produced (Bagøien \& Kiørboe 2005a, cf. also Eq. 4). For the pheromone cloud, the encounter cross section, as estimated by simulation analyses, is approximately proportional to the pheromone production rate (Fig. 10). Since mate encounter rate scales approximately with trail length, respectively cloud cross section (cf. above), it follows that the relative efficiencies of the 2 pheromone signal types are similar, regardless of copepod size.

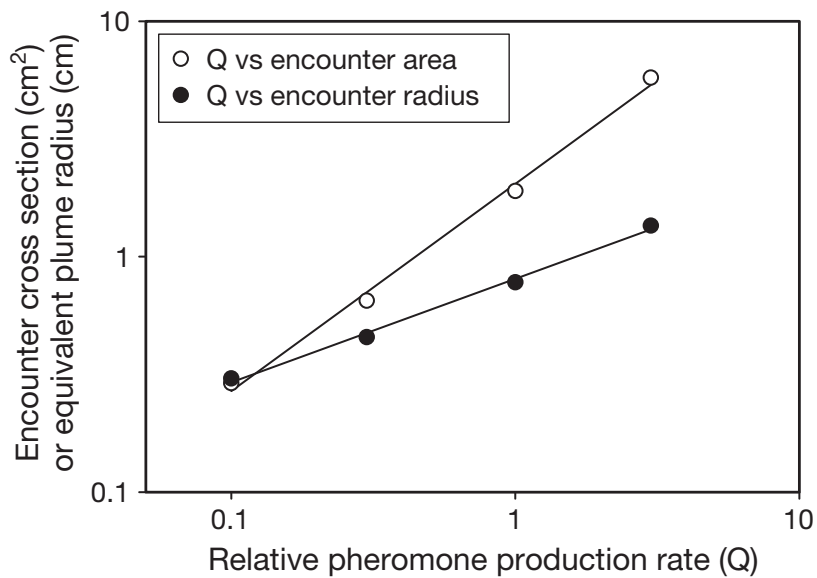

Fig. 10. Encounter cross section and equivalent spherical radius of a pheromone cloud as a function of relative pheromone production rate, $Q . Q=1$ corresponds to $Q / C^{*}=$ $10^{-3} \mathrm{~cm}^{3} \mathrm{~s}^{-1}$; parameters otherwise as in Table 1

\section{CONCLUSIONS}

Bagøien \& Kiørboe (2005a) reviewed the available information on chemical mate signalling in pelagic copepods and found that pheromone plumes produced by receptive females could be categorised as either trails or clouds. The 2 types have very different characteristics and elicit very different male behaviours. In Pseudocalanus elongatus, at least, the pheromone cloud appears to serve a dual purpose. In addition to providing an arena for an elaborate courtship of several minutes' duration, it attracts males and enhances the efficiency of mate finding in a dilute environment. The pheromone cloud in $P$. elongatus increases the encounter cross section of the female by a factor of about 40 or more. This is of the same magnitude as the enhancement of mate encounter rates that is achieved by similarly sized copepods that produce pheromone trails (Kiørboe \& Bagøien 2005). Thus, despite the striking differences, pheromone clouds and trails have essential characteristics in common, i.e. similar robustness to turbulence, similar scaling properties, and similar efficiencies in enhancing mate encounters. Trails or clouds thus do not appear to represent adaptations to different environments, but are probably simply functions of different motility characteristics caused by differences in feeding behaviour. However, the differences certainly add to the fascinating diversity of copepod behaviour.

Acknowledgements. T. K. and U. H. T. were supported by a grant from the Danish Natural Science Research Council (2101-0549), and E. B. was financed through a European Community Marie Curie post doctoral fellowship (\# MCFI-200201148). We are grateful to B. W. Frost for identifying the species studied in this paper as Pseudocalanus elongatus. 


\section{LITERATURE CITED}

Ambler JW, Broadwater SA, Buskey EJ, Peterson JO (1996) Mating behaviour in swarms of Dioithona oculata. In: Lenz PH, Hartline DK, Purcell JE, MacMillan DL (eds) Zooplankton: sensory ecology and physiology. Gordon \& Breach, Basel, p 287-299

Bagøien E, Kiørboe T (2005a) Blind dating - mate finding in planktonic copepods. I. Tracking the pheromone trail of Centropages typicus. Mar Ecol Prog Ser 300:105-115

Bagøien E, Kiørboe T (2005b) Blind dating - mate finding in planktonic copepods. III. Hydromechanical communication in Acartia tonsa. Mar Ecol Prog Ser 300:129-133

Batchelor GK (1967) An introduction to fluid dynamics. Cambridge Mathematical Library, Cambridge

Buskey EJ (1998) Components of mating behaviour in planktonic copepods. J Mar Syst 15:13-21

Denny MW (1993) Air and water. The biology and physics of life's media. Princeton University Press, Princeton, New Jersey

Doall MH, Colin SP, Strickler JR, Yen J (1998) Locating a mate in 3D: the case of Temora longicornis. Phil Trans R Soc Lond B 353:681-689

Griffiths AM, Frost BW (1976) Chemical communications in the marine planktonic copepods Calanus pacificus and Pseudocalanus sp. Crustaceana 30:1-9

Hamner WM (1990) Design developments in the planktonkreisel, a plankton aquarium for ships at sea. J Plankton Res 12:397-402

Hayward TL (1981) Mating and the depth distribution of an oceanic copepod. Limnol Oceanogr 26:374-377

Katona S (1973) Evidence for sex pheromones in planktonic copepods. Limnol Oceanogr 18:574-583
Kiørboe T, Bagøien E (2005) Motility patterns and mate encounter rates in planktonic copepods. Limnol Oceanogr 50(6):in press

Kiørboe T, Saiz E (1995) Planktivorous feeding in calm and turbulent environments, with emphasis on copepods. Mar Ecol Prog Ser 122:135-145

Nihongi A, Lovern SB, Strickler JR (2004) Mate-searching behaviors in the freshwater calanoid copepod Leptodiaptomus ashlandi. J Mar Syst 49:65-74

Ohtsuka S, Huys R (2001) Sexual dimorphism in calanoid copepods: morphology and function. Hydrobiologia 453/454: 441-466

Strickler JR (1998) Observing free-swimming copepods mating. Phil Trans R Soc Lond B 353:671-680

Tiselius P, Jonsson PR (1990) Foraging behaviour of 6 calanoid copepods. Observations and hydrodynamic analysis. Mar Ecol Prog Ser 66:23-33

Tsuda A, Miller CB (1998) Mate-finding behaviour in Calanus marshallae Frost. Phil Trans R Soc Lond B 353:713-720

Uchima M, Murano M (1988) Mating behaviour of the marine copepod Oithona davisae. Mar Biol 99:39-45

Visser AW (2001) Hydrodynamic signals in the plankton. Mar Ecol Prog Ser 222:1-24

Visser AW, Jackson GA (2004) Characteristics of the chemical plume behind a sinking particle in turbulent water. Mar Ecol Prog Ser 283:55-71

Weissburg MJ, Doall MH, Yen J (1998) Following the invisible trail: kinematic analysis of mate-tracking in the copepod Temora longicornis. Phil Trans R Soc Lond B 353: 701-712

Yen J, Weissburg MJ, Doall MH (1998) The fluid physics of signal perception by mate-tracking copepods. Phil Trans R Soc Lond B 353:387-804

Appendix 1. Numerical methods used to obtain the pheromone cloud in Fig. 8

The method is a particle-tracking algorithm, which follows a sequence of infinitesimal fluid elements as they depart from the female and move in the surrounding fluid. Each fluid element is initialised upon departure from the female with an amount of pheromones. As the fluid element is advected through the fluid, this puff of pheromone spreads by molecular diffusion and is further distorted by the velocity gradients. For the advective distortion of the puff, we consider only a linearisation of the flow field around the fluid element. Thus the distribution of the puff remains Gaussian, i.e. isosurfaces of the puff are ellipsoids. Furthermore, we take into consideration only the pure straining motion in the direction between a fluid element and its neighbours, and in the orthogonal plane. This is the dominant component of the local flow, and the simplification reduces the required computations significantly. Finally, at any point in time, the total concentration field of the pheromones is determined as the sum of the contributions from each puff.

Some further details of the method are as follows. When the female reorients herself, we let the direction of the female be piecewise constant in time, with reorientations occurring according to a Poisson process in time. Each orientation is sampled at random independently of previous orientations and uniformly distributed over a fraction of the sphere w.r.t. surface area. We assume that the fluid flow field relaxes to steady state instantaneously, so that at each discrete time step we take the fluid flow to be the Stokeslet associated with the instantaneous position and orientation of the female. We advect the fluid elements with an Euler scheme. For the first time step after a fluid element departs from the female, we use the analytical solution for the motion; in subsequent time steps, should the fluid element by chance come close to the female, we truncate the flow field to avoid the singularity at the origin of the Stokeslet.

For Fig. 8, we let the process run long enough for the initial transients to be disregarded; thus the figure can be taken to represent a sample from a random process with stationary statistics. The concentration field is evaluated on a regular 3D grid; the plume is subsequently determined from the threshold sensitivity of the male with the isosurface algorithm built into Matlab. The cross-section area of the plume in a given direction is obtained by visualising the plume on the computer screen, viewed from the given direction, and counting the number of pixels. 